Article

\title{
Effects of PEG-Induced Water Deficit in Solanum nigrum on Zn and Ni Uptake and Translocation in Split Root Systems
}

\section{Urs Feller ${ }^{1, *}$, Iwona Anders ${ }^{1}$ and Shuhe Wei ${ }^{2}$}

1 Institute of Plant Sciences and Oeschger Centre for Climate Change Research, University of Bern, Altenbergrain 21, CH-3013 Bern, Switzerland; E-Mail: iwona.anders@ips.unibe.ch

2 Key Laboratory of Pollution Ecology and Environmental Engineering, Institute of Applied Ecology, Chinese Academy of Sciences, Shenyang 110016, China; E-Mail: shuhewei@iae.ac.cn

* Author to whom correspondence should be addressed; E-Mail: urs.feller@ips.unibe.ch; Tel./Fax: +41-31-302-2109.

Academic Editor: Rujin Chen

Received: 14 April 2015 / Accepted: 1 June 2015 / Published: 5 June 2015

\begin{abstract}
Drought strongly influences root activities in crop plants and weeds. This paper is focused on the performance of the heavy metal accumulator Solanum nigrum, a plant which might be helpful for phytoremediation. The water potential in a split root system was decreased by the addition of polyethylene glycol (PEG 6000). Rubidium, strontium and radionuclides of heavy metals were used as markers to investigate the uptake into roots, the release to the shoot via the xylem, and finally the basipetal transport via the phloem to unlabeled roots. The uptake into the roots (total contents in the plant) was for most makers more severely decreased than the transport to the shoot or the export from the shoot to the unlabeled roots via the phloem. Regardless of the water potential in the labeling solution, ${ }^{63} \mathrm{Ni}$ and ${ }^{65} \mathrm{Zn}$ were selectively redistributed within the plant. From autoradiographs, it became evident that ${ }^{65} \mathrm{Zn}$ accumulated in root tips, in the apical shoot meristem and in axillary buds, while ${ }^{63} \mathrm{Ni}$ accumulated in young expanded leaves and roots but not in the meristems. Since both radionuclides are mobile in the phloem and are, therefore, well redistributed within the plant, the unequal transfer to shoot and root apical meristems is most likely caused by differences in the cell-to-cell transport in differentiation zones without functional phloem (immature sieve tubes).
\end{abstract}


Keywords: drought; transport; xylem; phloem; split root system; cations; heavy metals; radionuclides; Solanum nigrum L.

\section{Introduction}

During extended drought periods, species composition and productivity of grasslands are affected [1-6]. Plants are often exposed to strong soil water potential gradients $[7,8]$. Therefore, roots from the same plant may be in soil regions differing in their water availability. Experiments with split root systems might be helpful to elucidate interactions between differently stressed roots and the shoot. Markers applied to a part of the root system can be used to elucidate the uptake into the roots, the root-to-shoot transfer, and finally the basipetal transport via the phloem. Since the two parts of the root system can be subjected to different water potentials, such experiments may allow a deeper insight into the uptake into the roots, the transfer of the labels in the transpiration stream via the xylem to the shoot and the symplastic transport from the shoot to the other part of the root system via the phloem.

Organic compounds are not first choice as markers for such transport experiments, since they may be metabolized, insolubilized or converted to volatile compounds and released in gaseous form. Suitable markers should be stable, not metabolized, not phytotoxic and easily detectable (preferentially various labels in the same plants). Rubidium and strontium are useful non-radioactive labels, since they are not metabolized. Rubidium (similar to the macronutrient potassium) is highly mobile in xylem and phloem and is therefore well redistributed within the plant [9-11]. Strontium (similar to the macronutrient calcium) is loaded into the root xylem, reaches the shoot via the transpiration stream and accumulates in transpiring organs, since this element is characterized by a very poor phloem mobility [11-13]. Radionuclides of heavy metals were successfully used in the past for translocation experiments in wheat $[11,14,15]$, white lupin [16] and Solanum nigrum [17]. The release of several heavy metals $(\mathrm{Cd}$, $\mathrm{Co}, \mathrm{Mn}, \mathrm{Ni}$ and $\mathrm{Zn}$ ) from the roots to the shoot, the further redistribution within the shoot and the shootto-root transport in the phloem differed considerably between Triticum aestivum [11,14,15], Lupinus albus [16] and Solanum nigrum [17].

Various plant species or even varieties of the same species may be affected differently by drought $[1,3-8,18,19]$. As a consequence, the species composition in pastures may be altered during, and also for some time after, a summer drought [3-8]. Impacts of extended drought periods on edible crop plants [19-25], fodder plants [1,6-8,26-28] and weeds [3,29] were reported previously, but heavy metal hyperaccumulators were so far not the focus. Solanum nigrum was identified as a hyperaccumulator of $\mathrm{Cd}$ and other heavy metals [30]. This species might be helpful for the bioremediation of contaminated soils, although it is less efficient in cadmium accumulation than Sedum alfredii or Thlaspi caerulescens [30-34]. Solanum nigrum is known for an efficient root-to-shoot transport of heavy metals making it suitable for cleaning contaminated soils $[17,30]$. Therefore, the response of this species to drought stress is of practical relevance. Furthermore, this species with special heavy metal transport properties may be an interesting model system for basic physiological studies referring to source/sink interactions under drought. 
The aim of the investigations reported here was to identify in a split root system with Solanum nigrum the performance of the whole plant when only parts of the root system suffer from limited water availability considering (a) the uptake of cations into the roots, (b) the transport from the roots to the shoot with the transpiration stream in the xylem, and (c) further redistribution processes via the phloem within the shoot and between the shoot and the roots.

\section{Results and Discussion}

The root biomass remained quite constant during the labeling period of $96 \mathrm{~h}$, while the shoot biomass increased considerably (Figure 1). The shoot biomass at the end of the experiment was significantly higher in unstressed plants than in plants with one or both parts of the root system exposed to a lowered water potential. From these results, it became evident that the stress applied to the roots affected biomass production, although plants were still growing in all treatments.

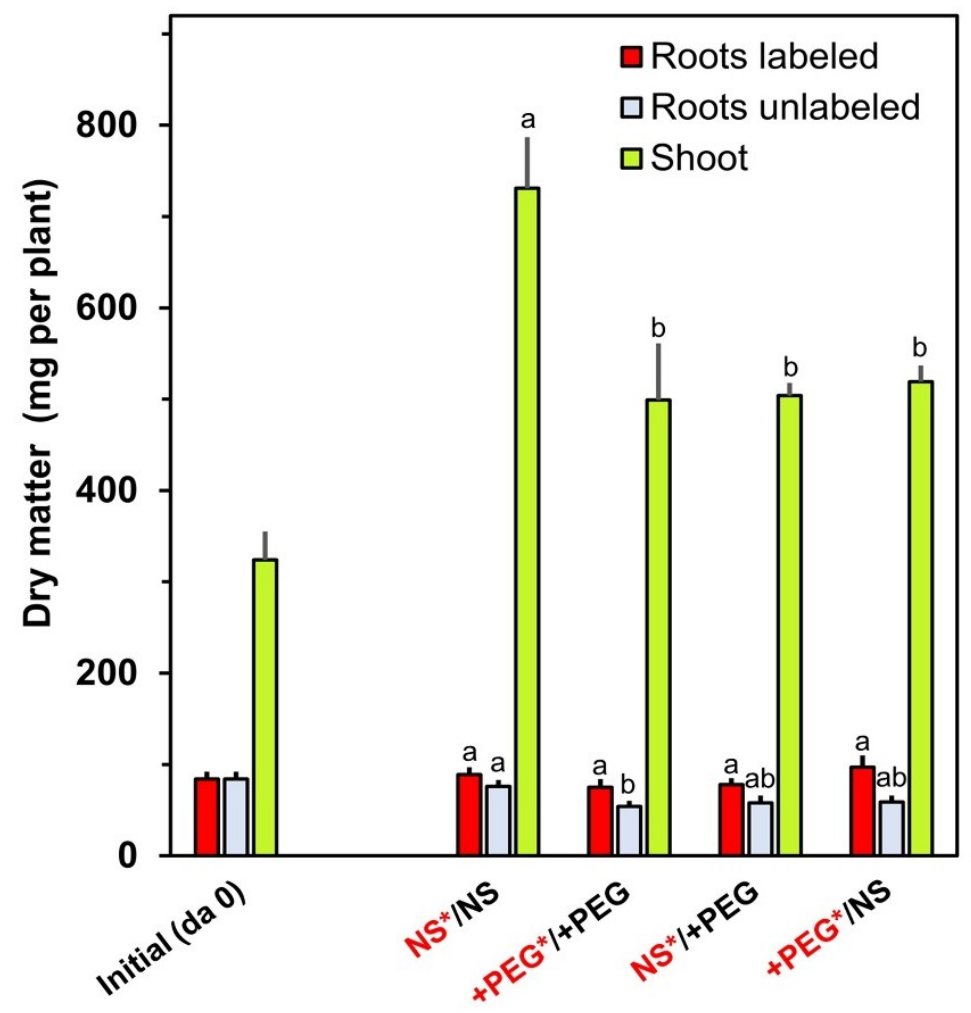

Figure 1. Dry matter in labeled roots, unlabeled roots and in the shoot before and after the exposure to the various treatments. Means + SE of six replicates are shown. Columns for a given plant part (roots labeled, roots unlabeled or shoot) with the same letter $(\mathrm{a}, \mathrm{b})$ are not significantly different at the $p<0.05$ level. NS: nutrient solution. +PEG: nutrient solution with polyethylene glycol 6000 . Red fonts: solution with labels.

Rubidium (similar to potassium) and strontium (similar to calcium) were present in the nutrient medium in excess from the beginning of the stress period (Figure 2). The uptake into the plants via the roots is the first physiological step in the acquisition of these elements. The translocation from the labeled roots to the shoot via the xylem is another important aspect (Figure 2). The two elements were more rapidly taken up by roots in standard nutrient medium than by those in PEG-containing medium (sum of 
black and orange columns). The total export of rubidium from labeled roots to the shoot via the transpiration stream was considerably higher in the absence of PEG leading to a high shoot/root ratio for this element. The shoot/root ratios for strontium contents were in PEG-containing medium similar to those measured for rubidium, but a large portion of the strontium taken up was retained in the labeled roots incubated in PEG-free medium. From these results, it became evident that the effects of a lowered water potential on uptake and release from the labeled roots to the shoot must be addressed in an elementspecific manner.
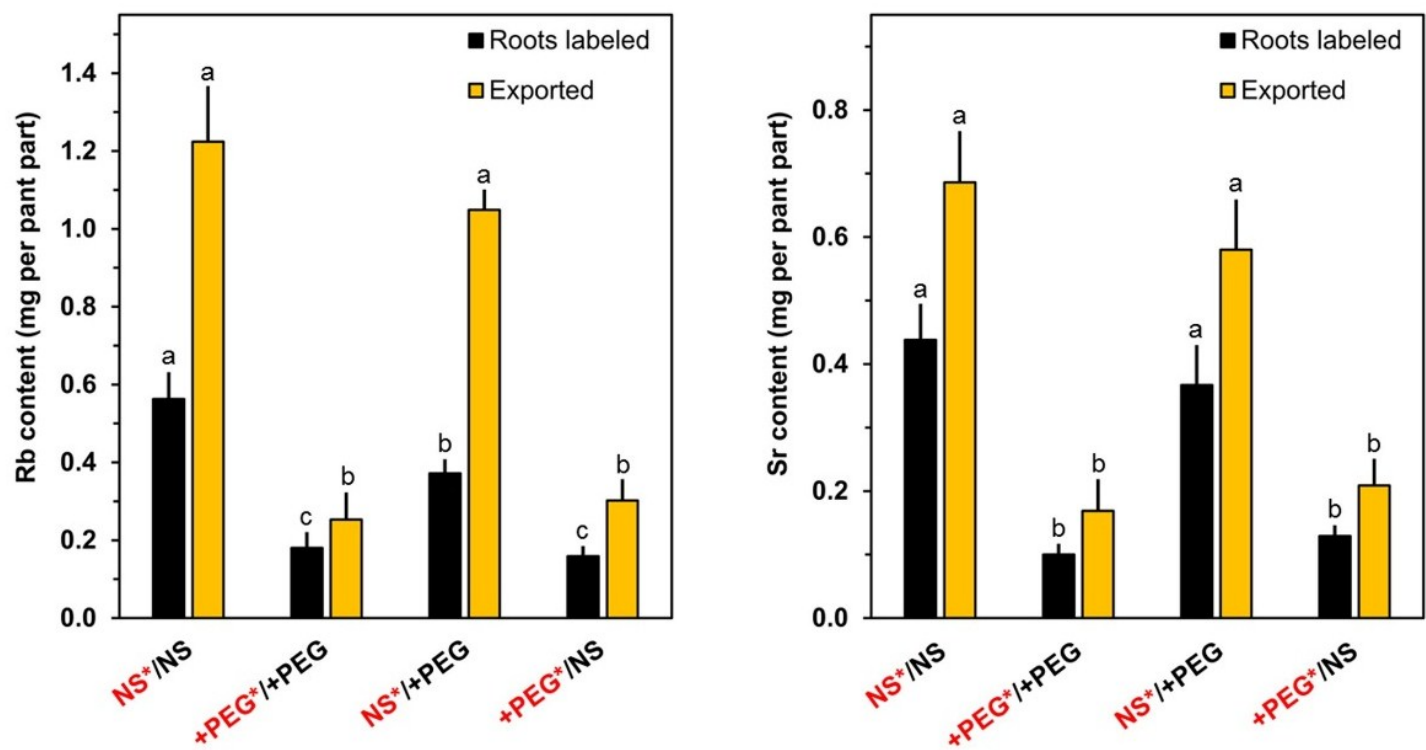

Figure 2. Contents of $\mathrm{Rb}$ and $\mathrm{Sr}$ in labeled roots and in the other plant parts (exported) after the incubation period of four days. $\mathrm{Rb}$ and $\mathrm{Sr}$ were added to the nutrient medium at the beginning of the PEG treatment (Day 0). Means + SE of six replicates are shown. Columns for a given plant part (roots labeled or exported) with the same letter $(a, b)$ are not significantly different at the $p<0.05$ level. NS: nutrient solution. +PEG: nutrient solution with polyethylene glycol 6000. Red fonts: solution with labels.

The heavy metals were added sequentially to the nutrient medium of one half of the split root system to allow a better resolution of the overall effects of artificial drought throughout the stress period (Figure 3). A strong retention in the labeled part of the roots system was observed for ${ }^{109} \mathrm{Cd}$ (added to the nutrient medium one day after the onset of the stress period). No significant differences between the various treatments were observed for the content of this radionuclide in the labeled roots. The export from the labeled roots was decreased when the water potential in the medium of the labeled roots was decreased, indicating that the root-to-shoot transfer was negatively influenced by artificial drought (similar to rubidium and strontium). The uptake of ${ }^{63} \mathrm{Ni}$ from the medium into the roots was decreased in droughtstressed plants. A high percentage of ${ }^{63} \mathrm{Ni}$ was released from the labeled roots to other plant parts under all experimental conditions. The largest quantities of ${ }^{63} \mathrm{Ni}$ were exported from the roots of unstressed plants. ${ }^{54} \mathrm{Mn}$ (added simultaneously with ${ }^{63} \mathrm{Ni}$ to the medium two days after the beginning of the stress period) was less efficiently released from the roots to other plant parts than ${ }^{63} \mathrm{Ni}$, but the overall response to the lowered water potential was similar for both radionuclides. ${ }^{65} \mathrm{Zn}$ was added to the nutrient medium three days after the onset of the artificial drought (one day before collecting and analyzing the plants). 
Although only a small quantity of this radionuclide was released from the roots to the shoot during this short period of one day, the overall response was very similar to that observed for ${ }^{109} \mathrm{Cd}$ indicating that the release from the labeled roots was affected by drought in a rather unspecific manner for the radionuclides tested.
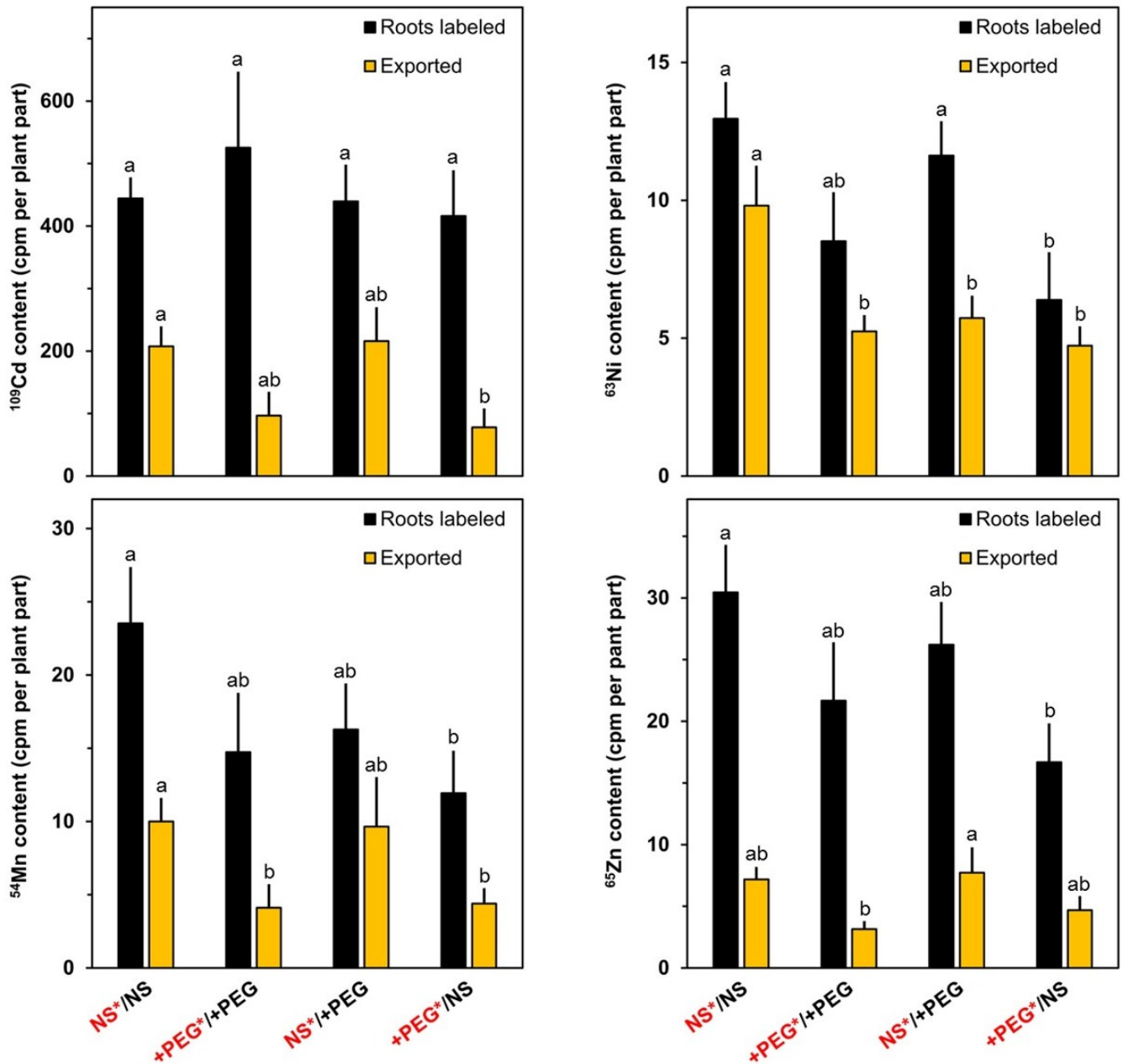

Figure 3. Contents of ${ }^{109} \mathrm{Cd},{ }^{63} \mathrm{Ni},{ }^{54} \mathrm{Mn}$ and ${ }^{65} \mathrm{Zn}$ in labeled roots and in the other plant parts (exported) after the incubation period of four days. ${ }^{109} \mathrm{Cd}$ was added at Day 1 ( $24 \mathrm{~h}$ after start of treatment), ${ }^{63} \mathrm{Ni}$ and ${ }^{54} \mathrm{Mn}$ were added at Day 2 (48 $\mathrm{h}$ after start of treatment) and ${ }^{65} \mathrm{Zn}$ was added at Day 3 (72 h after start of treatment). Means + SE of six replicates are shown. Columns for a given plant part (roots labeled or exported) with the same letter (a, b) are not significantly different at the $p<0.05$ level. NS: nutrient solution. +PEG: nutrient solution with polyethylene glycol 6000 . Red fonts: solution with labels.

The transfer from the roots to the shoot is based on the transpiration stream in the xylem and phloem mobility is not a crucial aspect in this context. However, the basipetal transport from the shoot to the unlabeled parts of the root system depends on phloem mobility. The percentage of the label in the plant transferred to the unlabeled parts of the roots system was highest for ${ }^{63} \mathrm{Ni}$ followed by ${ }^{65} \mathrm{Zn}$ which was added only one day before collecting the plants (Figure 4). For the other labels ( $\mathrm{Rb}, \mathrm{Sr},{ }^{109} \mathrm{Cd}$ and ${ }^{54} \mathrm{Mn}$ ), the relative contents in the unlabeled roots were far smaller in the unlabeled roots than in the shoot indicating a poor basipetal transport. 

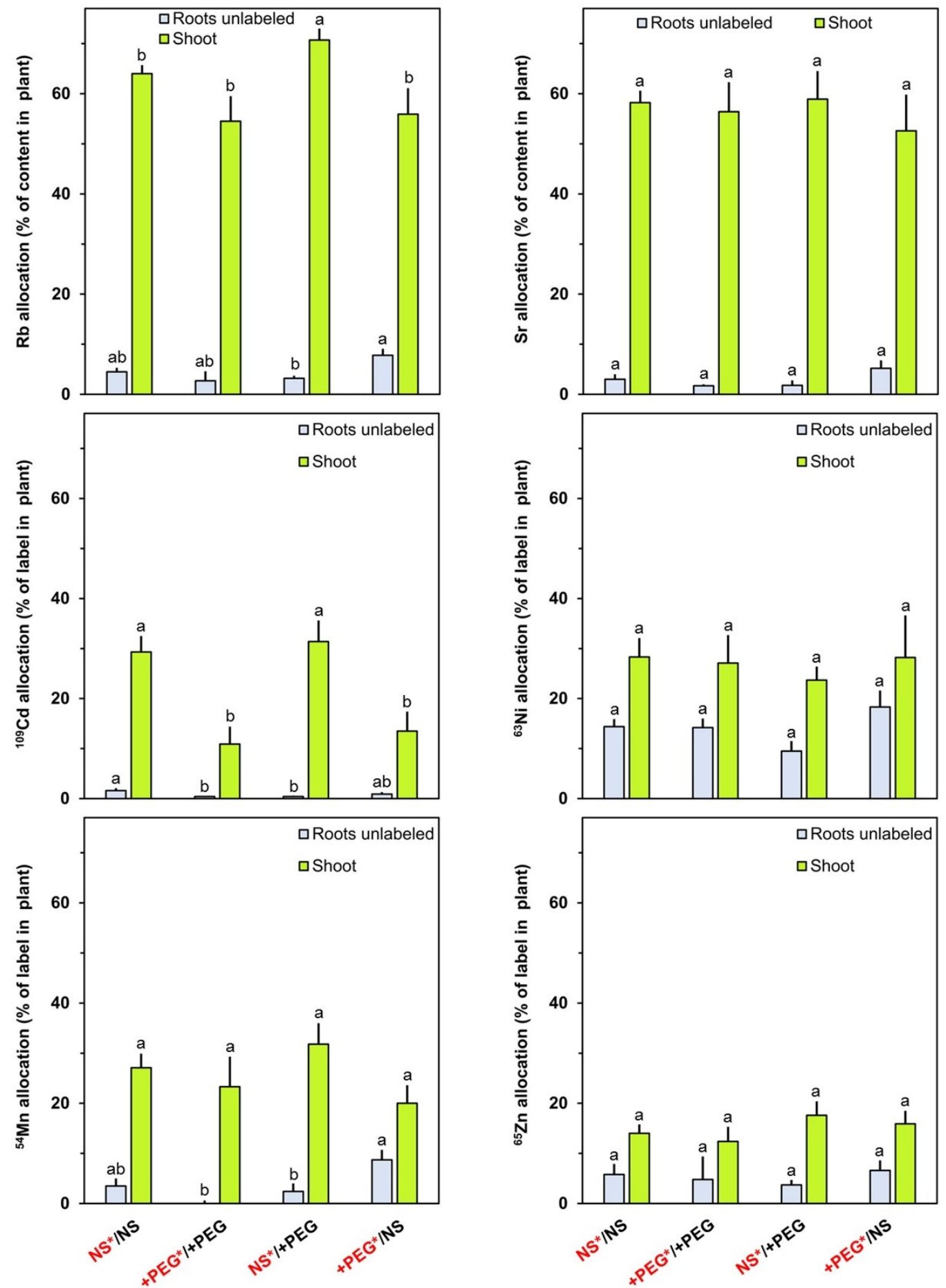

Figure 4. Allocation of $\mathrm{Rb}, \mathrm{Sr},{ }^{109} \mathrm{Cd},{ }^{63} \mathrm{Ni},{ }^{54} \mathrm{Mn}$ and ${ }^{65} \mathrm{Zn}$ to the shoot and to unlabeled roots after the incubation period of four days in percent of the total content per plant. $\mathrm{Rb}$ and $\mathrm{Sr}$ were present from the beginning of the treatment (Day 0), ${ }^{109} \mathrm{Cd}$ was added at Day $1(24 \mathrm{~h}$ after start of treatment), ${ }^{63} \mathrm{Ni}$ and ${ }^{54} \mathrm{Mn}$ were added at Day 2 (48 h after start of treatment) and ${ }^{65} \mathrm{Zn}$ was added at Day 3 (72 h after start of treatment). Means + SE of six replicates are shown. Columns for a given plant part (roots labeled or exported) with the same letter $(a, b)$ are not significantly different at the $p<0.05$ level. NS: nutrient solution. +PEG: nutrient solution with polyethylene glycol 6000 . Red fonts: solution with labels. 
The measurements mentioned above cannot answer the question how the various labels were distributed within the roots and within the shoot. Autoradiographs with ${ }^{63} \mathrm{Ni}$ and ${ }^{65} \mathrm{Zn}$ allowed a visualisation of the distribution patterns (Figure 5). Both radionuclides were detected in the labeled part of the root system and in younger leaves, while the unlabeled roots and the oldest leaves contained only traces. These findings are consistent with quantitative data mentioned above (Figures 2-4). However, the relative labeling of the roots tips, the youngest and still very small leaves and the axillary buds differed for these two radionuclides. While ${ }^{65} \mathrm{Zn}$ was strongly accumulated in meristems, this was not observed for ${ }^{63} \mathrm{Ni}$. To allow a better comparison, enlargements of shoot and root regions are shown in Figures 6 and 7.
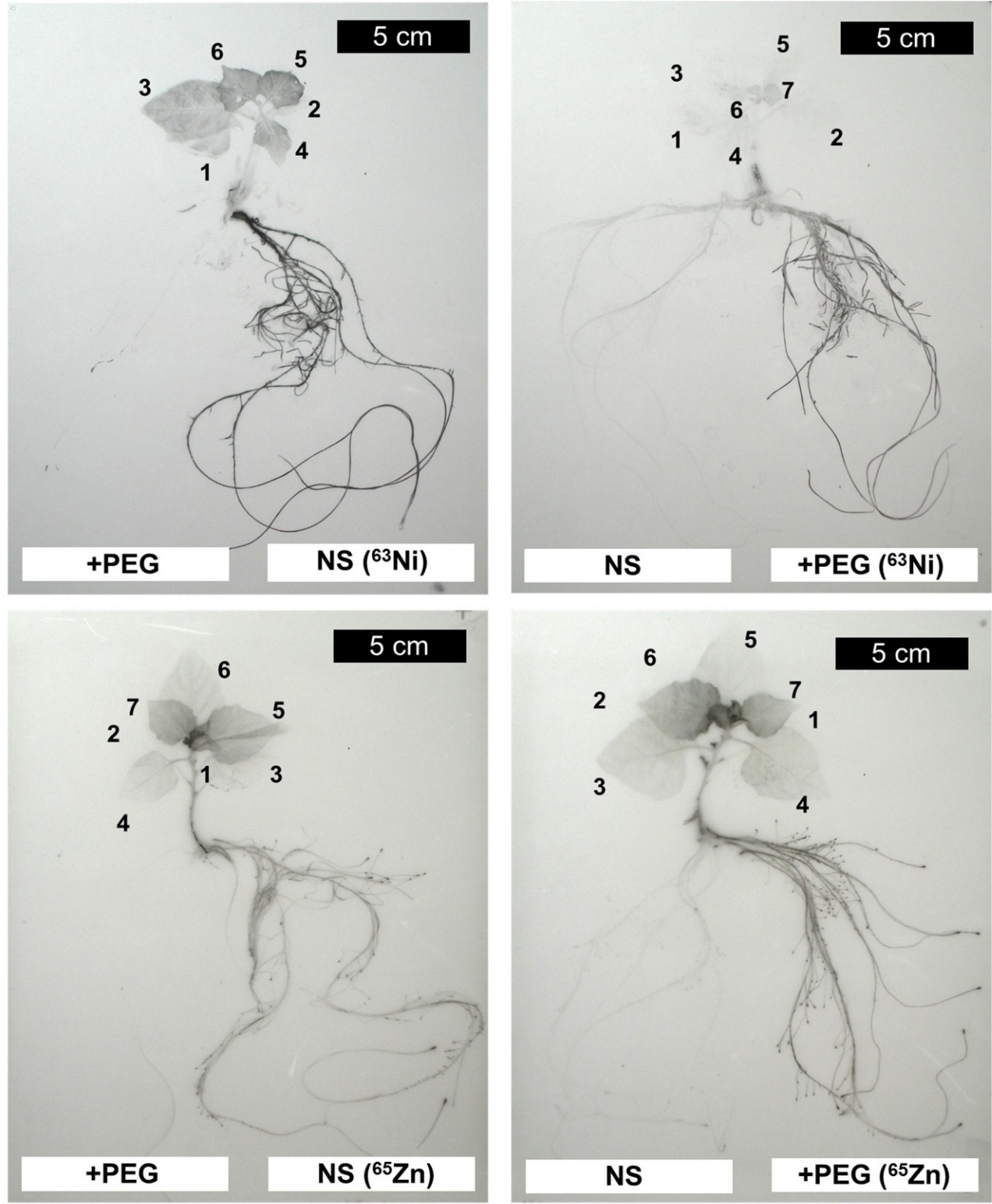

Figure 5. Autoradiographs of plants labeled for four days with ${ }^{63} \mathrm{Ni}$ or with ${ }^{65} \mathrm{Zn}$ in a split root system for two combinations of nutrient media. Cotyledons were no longer present at the beginning of the labeling phase. Leaves are numbered from the oldest (1) to the youngest (7). Only very weak signals were detected in the unlabeled roots and in the oldest two leaves $(1,2)$. NS: nutrient solution. +PEG: nutrient solution with polyethylene glycol 6000 . 
${ }^{63} \mathrm{Ni}$ was mainly located in the young expanded and expanding leaves but not in the youngest leaves and in the meristems (Figure 6). In contrast, ${ }^{65} \mathrm{Zn}$ was concentrated in youngest leaves and in axillary buds (Figure 6). The different distribution patterns for the two radionuclides were observed regardless of the presence of PEG in the labeling solution. A strong accumulation of ${ }^{65} \mathrm{Zn}$ (but not of ${ }^{63} \mathrm{Ni}$ ) was observed in the tips of the labeled roots (Figure 7). The accumulation of ${ }^{65} \mathrm{Zn}$ in the root tips was also observed in newly formed and in unlabeled roots, indicating that it was not just a consequence of a high uptake rate in the tip. ${ }^{63} \mathrm{Ni}$ and ${ }^{65} \mathrm{Zn}$ were reported to be highly phloem-mobile in various plants [14-17]. A possible explanation for the different distribution of ${ }^{63} \mathrm{Ni}$ and ${ }^{65} \mathrm{Zn}$ in roots and shoots could be based on differences in the cell-to-cell transport in plant parts not yet containing a functional phloem (meristematic regions). It must be borne in mind that the two micronutrients $\mathrm{Zn}$ and $\mathrm{Ni}$ are involved in different physiological processes [9,35]. Zinc is required for the activity of a series of enzymes (e.g., carbonic anhydrase, alcohol dehydrogenase, metalloproteinase, $\mathrm{Cu}-\mathrm{Zn}$ superoxide dismutase), while nickel is essential for urease activity (an enzyme important for purine catabolism releasing ammonium from urea) [9,35-37].
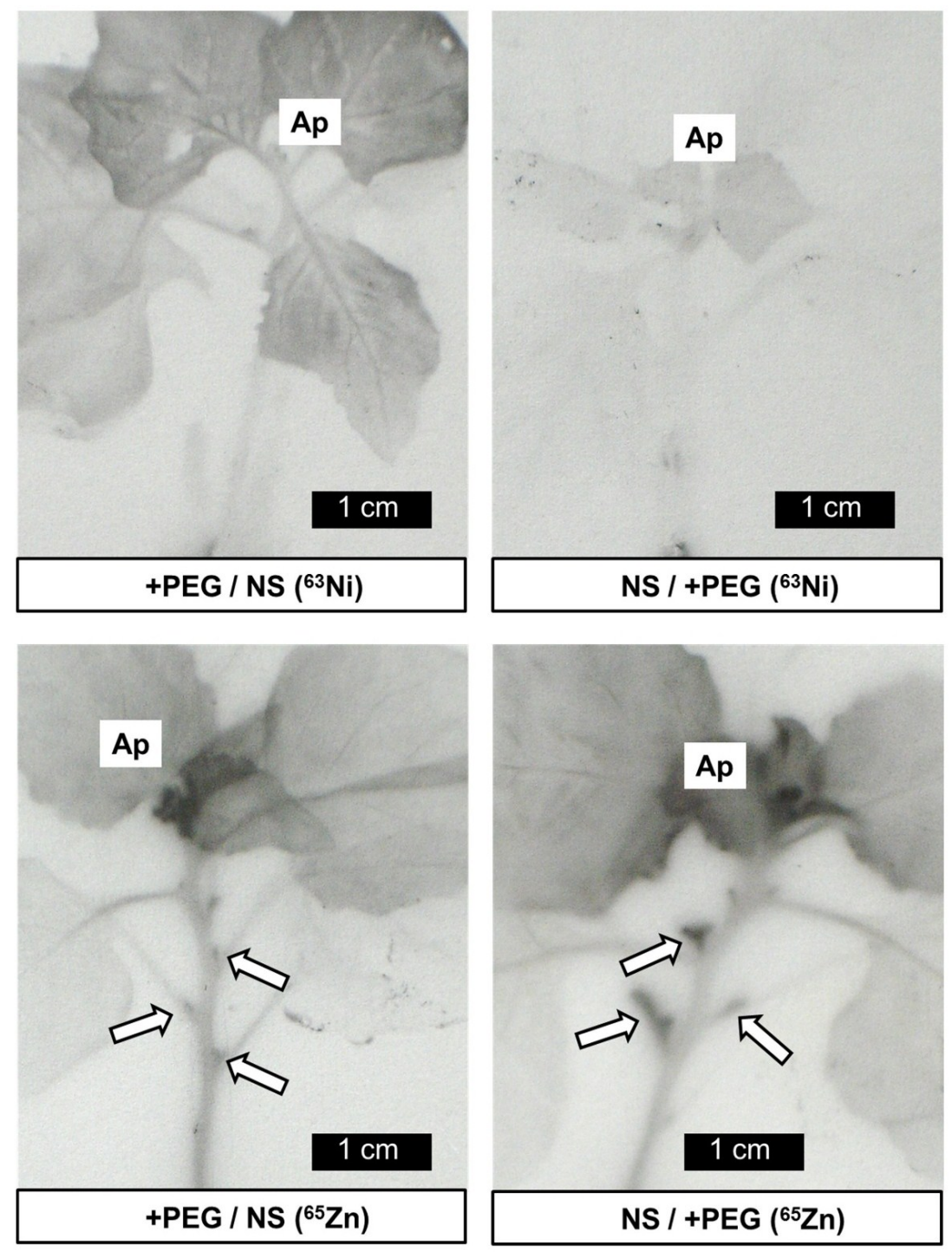

Figure 6. Autoradiographs of plants labeled for four days with ${ }^{63} \mathrm{Ni}$ or with ${ }^{65} \mathrm{Zn}$ in a split root system for two combinations of nutrient media (details from Figure 5). The apex (Ap) and axillary buds (arrows, for ${ }^{65} \mathrm{Zn}$ only) are indicated. 

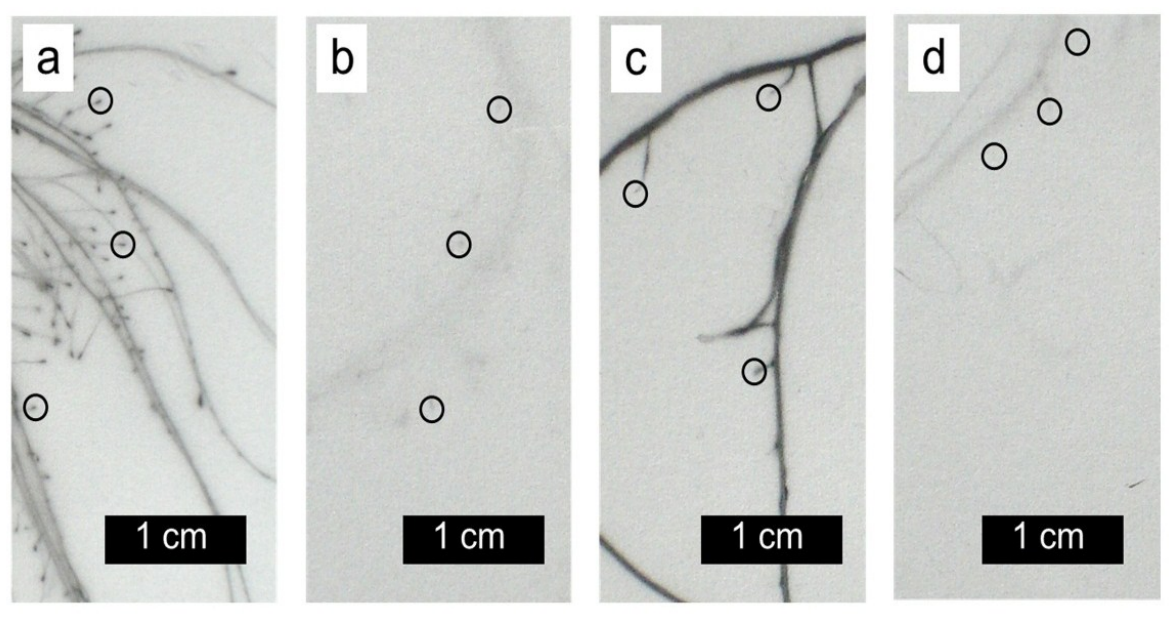

Figure 7. Autoradiographs (details from Figure 5) of labeled (a,c) and of unlabeled (b,d) roots in a split root system incubated for 4 days with ${ }^{65} \mathrm{Zn}$ in $(\mathbf{a}, \mathbf{b})$ or with ${ }^{63} \mathrm{Ni}(\mathbf{c}, \mathbf{d})$. The root medium was nutrient solution with polyethylene glycol (a) or nutrient solution without polyethylene glycol (b-d). Some root tips are encircled. Only very weak signals were detected in the unlabeled roots.

Shoot growth was negatively influenced when the roots were subjected to drought stress even when parts of the root system were not stressed (Figure 1). This effect might be caused by the production of abscisic acid in stressed roots and its transport via the xylem to the shoot causing stomatal closure, although sufficient water may be delivered from control roots to the shoot [38]. Under such conditions, transpiration and $\mathrm{CO}_{2}$ assimilation may be lowered and, as a consequence, biomass production may be negatively influenced.

The rapid transport of ${ }^{63} \mathrm{Ni}$ from the shoot to the unlabeled roots is consistent with the previously reported good mobility of $\mathrm{Ni}$ in the phloem in unstressed plants [14-17]. In addition to previous knowledge, the transport from drought-stressed (+PEG) to control roots and from control to drought-stressed roots was addressed in the experiments reported here. The transfer of $\mathrm{Rb}$ from stressed to unstressed roots was significantly higher than in the opposite direction (Figure 4). The same trends were observed for Ni and $\mathrm{Zn}$, although the differences were not significant. These findings indicate that the unstressed roots represented stronger phloem sinks than the stressed roots.

\section{Materials and Methods}

\subsection{Plant Material and Culture Conditions}

Solanum nigrum L. seeds were germinated as reported previously [17]. Briefly, dry seeds were soaked for one day in $0.1 \%(\mathrm{w} / \mathrm{v}) \mathrm{KNO}_{3}$ at $4{ }^{\circ} \mathrm{C}$ and then placed on tissue paper moistened with $0.1 \%(\mathrm{w} / \mathrm{v}) \mathrm{KNO}_{3}$. After $7 \mathrm{~d}$, the seedlings were transferred to standard nutrient medium [17]. Plants were exposed to a light/dark cycle with $14 \mathrm{~h}$ light $\left(200 \mu \mathrm{E} \mathrm{m}^{-2} \mathrm{~s}^{-1} ; 25^{\circ} \mathrm{C}\right)$ and $10 \mathrm{~h}$ darkness $\left(20^{\circ} \mathrm{C}\right)$. The root system was removed by a horizontal cut in the hypocotyl 20 (for autoradiography) or 21 (for $\gamma$-spectrometry) days after the beginning of germination. The part of the hypocotyl attached to the shoot was split with a vertical cut into two equal parts before the shoots were brought back to standard nutrient medium. This treatment led to the formation of a split root system with two equally developed parts. The labeling 
experiment for $\gamma$-spectrometry was started $38 \mathrm{~d}$ after seed soaking, while smaller plants (28 days after seed soaking) were labeled for autoradiography.

\subsection{Experimental Setup and Quantification of Labels}

Two rectangular plastic containers with $150 \mathrm{~mL}$ standard nutrient medium were used for each set containing two plants with a split root system. When indicated (+PEG), 15 g polyethylene glycol 6000 were added to the $150 \mathrm{~mL}$ nutrient medium to lower the water potential $[39,40]$. The calculated initial water potential of the +PEG solution was $-0.16 \mathrm{MPa}[39,40]$. The labels ( $\mathrm{Rb}$ as $\mathrm{RbCl}, \mathrm{Sr}$ as $\mathrm{SrCl}_{2},{ }^{109} \mathrm{Cd}$, ${ }^{63} \mathrm{Ni},{ }^{54} \mathrm{Mn}$ and ${ }^{65} \mathrm{Zn}$ ) were added only to one of these containers as indicated. The plants used for this experiment were $38 \mathrm{~d}$ old. $\mathrm{Rb}$ and $\mathrm{Sr}$ were added at the beginning of the labeling phase (Day 0). The radionuclides were added from aqueous stock solutions $1 \mathrm{~d}\left({ }^{109} \mathrm{Cd}\right), 2 \mathrm{~d}\left({ }^{63} \mathrm{Ni},{ }^{54} \mathrm{Mn}\right)$ or $3 \mathrm{~d}\left({ }^{65} \mathrm{Zn}\right)$ after the start of the labeling phase. The incubation conditions during the labeling phase were identical with those described above under Section 3.1. All plants were collected at Day 4 (4 d after the beginning of the labeling phase) and separated into shoot, labeled roots and unlabeled roots. The samples were dried in polystyrene tubes in an oven at $60^{\circ} \mathrm{C}$.

The $\gamma$-emitting radiolabels ${ }^{109} \mathrm{Cd},{ }^{54} \mathrm{Mn}$ and ${ }^{65} \mathrm{Zn}$ were quantified in the dried plant samples simultaneously with a $\gamma$-spectrometer (1480 Wizard 3', Wallac Oy, Turku, Finland). Afterwards, the dry weights of the samples were taken, and the plant material was transferred to glass tubes for dry ashing ( 2 times for $8 \mathrm{~h}$ at $550^{\circ} \mathrm{C}$ ), as described by Page and Feller [14]. After cooling, $0.3 \mathrm{~mL} 10 \mathrm{~N} \mathrm{HCl}$ were added to each tube. After mixing, $3 \mathrm{~mL}$ deionized $\mathrm{H}_{2} \mathrm{O}$ were added. For the quantification of the $\beta$-emitter ${ }^{63} \mathrm{Ni}, 0.2 \mathrm{~mL}$ of the well-mixed solutions were transferred to Ready Caps (Beckman Instruments, Fullerton, CA, USA). After drying the samples for $4 \mathrm{~h}$ at $60{ }^{\circ} \mathrm{C}$, they were analyzed in a scintillation counter. The same solutions as for ${ }^{63} \mathrm{Ni}$ were used for the detection of $\mathrm{Rb}$ and $\mathrm{Sr}$ by atomic spectrometry after appropriate dilution with $1000 \mathrm{ppm} \mathrm{Cs}$ as $\mathrm{CsCl}$ in $0.1 \mathrm{~N} \mathrm{HCl}$ (for $\mathrm{Rb}$ ) or with 5000 ppm $\mathrm{La}$ as $\mathrm{LaCl}_{3}$ in $0.1 \mathrm{~N} \mathrm{HCl}$ (for Sr) as reported previously [11,14].

Means and standard errors of 6 replicate plants are shown in the figures. Significant differences between different treatments were identified with Student's t-test. Columns with the same letter $(\mathrm{a}-\mathrm{c})$ are not significantly different at the $p<0.05$ level.

\subsection{Autoradiography and Localization of ${ }^{63} \mathrm{Ni}$ and ${ }^{65} \mathrm{Zn}$}

The labeling phase for autoradiography started when the plants were $28 \mathrm{~d}$ old and separate plants were used for the two radionuclides ${ }^{63} \mathrm{Ni}$ and ${ }^{65} \mathrm{Zn}$. The same experimental setup as mentioned above under Section 3.2 was used, but the radionuclides were present in the nutrient medium for one part of the root system from the beginning of the labeling period of $4 \mathrm{~d}$. Rb and Sr were not added to the nutrient medium. After the labeling phase, the plants were dried with tissue paper keeping the various parts of the root system well separated and then completely dried between several layers of tissue paper by ironing. The dry plants were the mounted on cardboard for the exposure to an x-ray film for 5 months in darkness. 


\section{Conclusions}

Artificial drought strongly decreased the uptake of most elements considered in the plant and the release to the shoot, while the transfer to unlabeled roots was very low in Solanum nigrum and far less influenced by the water potential. Ni was an exception, since it was well redistributed and transported via the phloem to the unlabeled roots. No drastic effects of the water potential in the medium on the sink strength of unlabeled roots were detected after an incubation period of four days. However, there was a significant difference $(\mathrm{Rb})$ and a clear trend $\left({ }^{63} \mathrm{Ni}\right.$ and $\left.{ }^{65} \mathrm{Zn}\right)$ in favor of the supply of unstressed roots. This difference might become more relevant during longer exposure times and might be involved in better root growth in soil regions with a less negative water potential.

Autoradiographs allowed the visualization of the radionuclide distribution in the roots and in the shoot. The different distribution patterns for ${ }^{63} \mathrm{Ni}$ and ${ }^{65} \mathrm{Zn}$ remain to be investigated in more detail in future experiments, since it was observed in various plant species and was highly reproducible in Solanum nigrum as well as in wheat or legumes $[14,16]$. The anatomy of roots and shoots may explain the observed differences [41]. ${ }^{63} \mathrm{Ni}$ and ${ }^{65} \mathrm{Zn}$ are easily transported in the phloem [14-17]. Therefore, the long-distance transport is presumably very similar, but in the root tip, in the shoot apex and in axillary buds, the phloem is not yet differentiated and can therefore not yet be functional. In these regions, the ions must be transported from cell to cell, and it must be hypothesized that this short-distance cell-to-cell transport is different for ${ }^{63} \mathrm{Ni}$ and ${ }^{65} \mathrm{Zn}$. The mechanisms involved in $\mathrm{Ni}$ and $\mathrm{Zn}$ transport at the cellular and subcellular level are not yet clear and their elucidation represents a challenge for further investigations.

\section{Acknowledgments}

We thank Valérie Page for stimulating discussions and technical hints. The work was partially supported by the Sino Swiss Science and Technology Cooperation (SSSTC, Project EG-06-092011).

\section{Author Contributions}

U.F. coordinated the investigations, was involved in experimental work and wrote major parts of the manuscript. I.A. grew the plants and contributed to plant analyses. S.W. contributed basic knowledge concerning the species used for the experiments and was involved in preparing the manuscript. All authors were involved in finalizing the manuscript.

\section{Conflicts of Interest}

The authors declare no conflict of interest.

\section{References}

1. Cantarel, A.A.M.; Bloor, J.M.G.; Sousanna, J.-F. Four years of simulated climate change reduces above-ground productivity and alters functional diversity in a grassland ecosystem. J. Veg. Sci. 2013, 24, 113-126, doi:10.1111/j.1654-1103.2012.01452.x. 
2. Burri, S.; Sturm, P.; Prechsl, U.E.; Knohl, A.; Buchmann, N. The impact of extreme summer drought on the short-term carbon coupling of photosynthesis to soil $\mathrm{CO}_{2}$ efflux in a temperate grassland. Biogeosciences 2014, 11, 961-975, doi:10.5194/bg-11-961-2014.

3. Gilgen, A.K.; Signarbieux, C.; Feller, U.; Buchmann, N. Competitive advantage of Rumex obtusifolius L. might increase in intensively managed temperate grasslands under dryer climate. Agric. Ecosyst. Environ. 2010, 135, 15-23, doi:10.1016/j.agee.2009.08.004.

4. Van den Berge, J.; Naudts, K.; de Boeck, H.J.; Ceulemans, R.; Nijs, I. Do interactions with neighbours modify the above-ground productivity response to drought? A test with two grassland species. Environ. Exp. Bot. 2014, 105, 18-24, doi:10.1016/j.envexpbot.2014.04.002.

5. Grant, K.; Kreyling, J.; Heilmeier, H.; Beierkuhnlein, C.; Jentsch, A. Extreme weather events and plant-plant interactions: Shifts between competition and facilitation among grassland species in the face of drought and heavy rainfall. Ecol. Res. 2014, 29, 991-1001, doi:10.1007/s11284-014-1187-5.

6. Khan, M.A.A.; Grant, K.; Beierkuhnlein, C.; Kreyling, J.; Jentsch, A. Climatic extremes lead to species-specific legume facilitation in an experimental temperate grassland. Plant Soil 2014, 379, 161-175, doi:10.1007/s11104-014-2050-8.

7. Bollig, C.; Feller, U. Impacts of drought stress on water relations and carbon assimilation in grassland species at different altitudes. Agric. Ecosyst. Environ. 2014, 188, 212-220.

8. Signarbieux, C.; Feller, U. Effects of an extended drought period on physiological properties of grassland species in the field. J. Plant Res. 2012, 125, 251-261, doi:10.1007/s10265-011-0427-9.

9. Marschner, H. Mineral Nutrition of Higher Plants, 2nd ed.; Academic Press: London, UK, 1995; p. 38.

10. Vallejo, A.J.; Peralta, M.L.; Santa-Maria, G.E. Expression of potassium-transporter coding genes, and kinetics of rubidium uptake, along a longitudinal root axis. Plant Cell Environ. 2005, 28, 850-862, doi:10.1111/j.1365-3040.2005.01334.x.

11. Herren, T.; Feller, U. Transport of cadmium via xylem and phloem in maturing wheat shoots: Comparison with the translocation of zinc, strontium and rubidium. Ann. Bot. 1997, 80, 623-628, doi:10.1006/anbo.1997.0492.

12. Tyson, M.J.; Sheffield, E.; Callaghan, T.V. Uptake, allocation, accumulation and ecological implications of Sr-85 in bracken (Pteridium aquilinum L.-Kuhn). J. Environ. Radioact. 1999, 46, 15-25, doi:10.1016/S0265-931X(98)00154-4.

13. Seregin, I.V.; Kozhevnikova, A.D. Strontium transport, distribution, and toxic effects on maize seedling growth. Russ. J. Plant Physiol. 2004, 51, 215-221, doi:10.1023/B:RUPP.0000019217.89936.e7.

14. Page, V.; Feller, U. Selective transport of zinc, manganese, nickel, cobalt and cadmium in the root system and transfer to the leaves in young wheat plants. Ann. Bot. 2005, 96, 425-434.

15. Riesen, O.; Feller, U. Redistribution of nickel, cobalt, manganese, zinc and cadmium via the phloem in young and maturing wheat. J. Plant Nutr. 2005, 28, 421-430, doi:10.1081/PLN-20049153.

16. Page, V.; Weisskopf, L.; Feller, U. Heavy metals in white lupin: Uptake, root-to-shoot transfer and redistribution within the plant. New Phytol. 2006, 171, 329-341, doi:10.1111/j.1469-8137.2006.01756.x.

17. Wei, S.; Anders, I.; Feller, U. Selective uptake, distribution, and redistribution of Cd-109, Co-57, $\mathrm{Zn}-65, \mathrm{Ni}-63$, and Cs-134 via xylem and phloem in the heavy metal hyperaccumulator Solanum nigrum L. Environ. Sci. Pollut. Res. 2014, 21, 7624-7630, doi:10.1007/s11356-014-2636-y.

18. Volaire, F. Drought survival, summer dormancy and dehydrin accumulation in contrasting cultivars of Dactylis glomerata. Physiol. Plant. 2002, 116, 42-51, doi:10.1034/j.1399-3054.2002.1160106.x. 
19. Simova-Stoilova, L.; Demirevska, K.; Petrova, T.; Tsenov, N.; Feller, U. Antioxidative protection and proteolytic activity in tolerant and sensitive wheat (Triticum aestivum L.) varieties subjected to long-term field drought. Plant Growth Regul. 2009, 58, 107-117, doi:10.1007/s10725-008-9356-6.

20. Plaut, Z.; Butow, B.J.; Blumenthal, C.S.; Wrigley, C.W. Transport of dry matter into developing wheat kernels and its contribution to grain yield under post-anthesis water deficit and elevated temperature. Field Crops Res. 2004, 86, 185-198, doi:10.1016/j.fcr.2003.08.005.

21. Bencze, S.; Bamberger, Z.; Janda, T.; Balla, K.; Varga, B.; Bedo, Z.; Veisz, O. Physiological response of wheat to elevated atmospheric $\mathrm{CO}_{2}$ and low water supply levels. Photosynthetica 2014, 52, 71-82, doi:10.1007/s11099-014-0008-y.

22. Demirevska, K.; Simova-Stoilova, L.; Vassileva, V.; Feller, U. Rubisco and some chaperone protein responses to water stress and rewatering at early seedling growth of drought sensitive and tolerant wheat varieties. Plant Growth Regul. 2008, 56, 97-106, doi:10.1007/s10725-008-9288-1.

23. Grigorova, B.; Vaseva, I.; Demirevska, K.; Feller, U. Combined drought and heat stress in wheat: Changes in some heat shock proteins. Biol. Plant. 2011, 55, 105-111, doi:10.1007/s10535-011-0014-X.

24. Vassileva, V.; Simova-Stoilova, L.; Demirevska, K.; Feller, U. Variety-specific response of wheat (Triticum aestivum L.) leaf mitochondria to drought stress. J. Plant Res. 2009, 122, 445-454, doi:10.1007/s10265-009-0225-9.

25. Vassileva, V.; Signarbieux, C.; Anders, I.; Feller, U. Genotypic variation in drought stress response and subsequent recovery of (Triticum aestivum L.). J. Plant Res. 2011, 124, 147-154.

26. Cougnon, M.; Baert, J.; van Waes, C.; Reheul, D. Performance and quality of of tall fescue (Festuca arundinacea Schreb.) and perennial ryegrass (Lolium perenne L.) and mixtures of both species grown with or without white clover (Trifolium repens L.) under cutting management. Grass Forage Sci. 2014, 69, 666-677, doi:10.1111/gfs.12102.

27. Turner, L.R.; Holloway-Phillips, M.M.; Rawnsley, R.P.; Donaghy, D.J.; Pembleton, K.G. The morphological and physiological responses of perennial ryegrass (Lolium perenne L.), cocksfoot (Dactylis glomerata L.) and tall fescue (Festuca arundinacea Schreb.; syn. Schoedonorus phoenix Scop.) to variable water availability. Grass Forage Sci. 2012, 67, 507-518.

28. Feller, U.; Vaseva, I.I. Extreme climatic events: Impacts of drought and high temperature on physiological processes in agronomically important plants. Front. Environ. Sci. 2014, 2, 39.

29. Gilgen, A.K.; Feller, U. Drought stress alters solute allocation in broadleaf dock (Rumex obtusifolius). Weed Sci. 2013, 61, 104-108, doi:10.1614/ws-d-12-00074.1.

30. Wei, S.; Zhou, Q.X.; Koval, P.V. Flowering stage characteristics of cadmium hyperaccumulator Solanum nigrum L. and their significance to phytoremediation. Sci. Total Environ. 2005, 369, 441-446, doi:10.1016/j.scitotenv.2006.06.014.

31. Yang, X.E.; Long, X.X.; Ye, Z.L.; Calvert, D.V.; Stoffella, P.J. Cadmium tolerance and hyperaccumulation in a new Zn-hyperaccumulator (Sedum alfredii Hance). Plant Soil 2004, 259, 181-189, doi:10.1023/B:PLSO.0000020956.24027.f2.

32. Brown, S.L.; Chaney, R.L.; Angle; J.S.; Baker, A.J.M. Zinc and cadmium uptake by hyperaccumulator Thlaspi caerulescens grown in nutrient solution. Soil Sci. Soc. Am. J. 1995, 59, 125-133.

33. Chaney, R.L.; Malik, M.; Li, Y.M.; Brown, S.L.; Brewer, E.P.; Angle, J.S.; Baker, A.J.M. Phytoremediation of soil metals. Curr. Opin. Biotechnol. 1997, 8, 279-284. 
34. Wei, S.; Zhou, Q.X.; Wang, X.; Zhang, K.S.; Guo, G.L.; Ma, Q.Y.L. A newly-discovered Cd-hyperaccumulator Solanum nigrum L. Chin. Sci. Bull. 2005, 50, 33-38, doi:10.1360/982004-292.

35. Hänsch, R.; Mendel, R.R. Physiological functions of mineral micronutrients $(\mathrm{Cu}, \mathrm{Zn}, \mathrm{Mn}, \mathrm{Fe}, \mathrm{Ni}$, Mo, B, Cl). Curr. Opin. Plant Biol. 2009, 12, 259-266, doi:10.1016/j.pbi.2009.05.006.

36. Gerendas, J.; Polacco, J.C.; Freyermuth, S.K.; Sattelmacher, B. Significance of nickel for plant growth and metabolism. J. Plant Nutr Soil Sci.-Z. Pflanzenernähr. Bodenk. 1999, 162, 241-256.

37. Bai, C.; Liu, L.P.; Wood, B.W. Nickel affects xylem sap RNase and converts RNase A to a urease. BMC Plant Biol. 2013, 13, 207, doi:10.1186/1471-2229-13-207.

38. Gowing, D.J.G.; Davies, W.J.; Jones, H.G. A positive root-sourced signal as an indicator of soil drying in apple, Malus $x$ domestica Borkh. J. Exp. Bot. 1990, 41, 1535-1540.

39. Steuter, A.A.; Mozafar, A.; Goodin, J.R. Water potential of aqueous polyethylene glycol. Plant Physiol. 1981, doi:10.1104/pp.67.1.64.

40. Michel, B.E.; Kaufmann, M.R. The osmotic potential of polyethylene glycol 6000. Plant Physiol. 1973, 51, 914-916, doi:10.1104/pp.51.5.914.

41. Fahn, A. Plant Anatomy, 3rd ed.; Pergamon Press: Oxford, UK, 1982; pp. 46-73.

(C) 2015 by the authors; licensee MDPI, Basel, Switzerland. This article is an open access article distributed under the terms and conditions of the Creative Commons Attribution license (http://creativecommons.org/licenses/by/4.0/). 